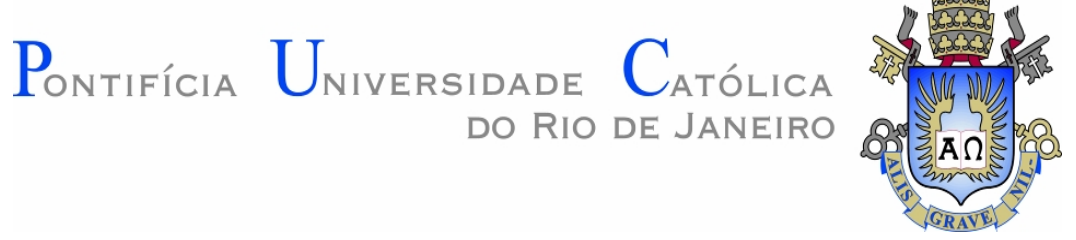

Raquel Pereira Alberto Nunes

\title{
Barravento(s): uma análise comparativa de roteiros
}

Dissertação apresentada como requisito parcial para obtenção do grau de Mestre pelo Programa de Pós Graduação em História Social da Cultura, do Departamento de História da PUC-Rio.

Orientador: Prof. Luís Reznik 


\section{Raquel Pereira Alberto Nunes}

\section{Barravento(s): uma análise comparativa de roteiros}

Dissertação apresentada como requisito parcial para obtenção do grau de Mestre pelo Programa de PósGraduação em História Social da Cultura do Departamento de História do Centro de Ciências Sociais da PUC-Rio. Aprovada pela Comissão Examinadora abaixo assinada.

Prof. Luís Reznik

Orientador

Departamento de História

PUC-Rio

Prof. Ismail Norberto Xavier

Departamento de Cinema Rádio e Televisão

USP

Prof. Leonardo Affonso de Miranda Pereira Departamento de História

PUC-Rio

Prof ${ }^{a}$ Mônica Herz

Vice-Decana de Pós-Graduação do Centro de Ciências Sociais

PUC-Rio

Rio de Janeiro, 31 de maio de 2011 
Todos os direitos reservados. É proibida a reprodução total ou parcial do trabalho sem autorização da universidade, da autora e do orientador.

\section{Raquel Pereira Alberto Nunes}

Graduou-se em História pela Universidade Federal Fluminense, em 2007. Finaliza graduação em Comunicação Social, habilitação Radialismo/TV, pela Universidade Federal do Rio de Janeiro em 2011. Participou de congressos, encontros, palestras e colóquios nas áreas de História, com ênfase em História Contemporânea e Cinema.

Ficha Catalográfica

Nunes, Raquel Pereira Alberto

Barravento(s): uma análise comparativa de roteiros / Raquel Pereira Alberto Nunes ; orientador: Luís Reznik. - 2011. 160 f. ; $30 \mathrm{~cm}$

Dissertação (mestrado)-Pontifícia Universidade Católica do Rio de Janeiro, Departamento de História, 2011.

Inclui bibliografia

1. História - Teses. 2. História social da cultura. 3. Cultura popular. 4. Alienação. 5. Ciclo de cinema baiano. 6. Identidade nacional. I. Reznik, Luís. II. Pontifícia Universidade Católica do Rio de Janeiro. Departamento de História. III. Título. 


\section{Agradecimentos}

Buscando uma ordem cronológica, devo iniciar agradecendo a Ney Santana, sem o qual este trabalho não teria sido possível. Ney foi responsável por me colocar em contato com Luiz Paulino dos Santos, o que reacendeu em mim a esperança de encontrar o roteiro original e concretizar esta pesquisa.

Ao pessoal da Funarte, por ter preservado o roteiro de Paulino e mantido-o disponível sempre que necessário. À Cinemateca Brasileira também agradeço a manutenção do acervo e o ótimo atendimento. Ao Tempo Glauber, especialmente Ruy Gardnier, por ter sido tão solícito e pronto a ajudar.

À Mônica Kornis, professora do CPDOC-FGV, e Roberto Moura, professor de Cinema da UFF, que mantiveram diálogo comigo desde o início da faculdade e me iniciaram no assunto "cinema para historiadores", colocando-se 
sempre à disposição para trocas e leituras críticas. À Mônica, um agradecimento especial pelo carinho e pela grande força, não só para a pesquisa, como também para a pesquisadora.

Ao professor Ismail Xavier devo meu sincero reconhecimento. Foi de uma nota de rodapé sua que minha dissertação nasceu. Agradeço por aceitar ser da minha banca e, de alguma forma, fazer com que o trabalho retorne a seu ponto de origem.

A meu orientador, por todo apoio, desde o início. Por acreditar que o projeto era bom e confiar em mim, mostrando-se tão aberto e amigo. Um eterno muito obrigada. Você fica na memória para sempre - ou enquanto ela durar (rs).

Aos amigos que, entendendo a etapa pela qual passei nos últimos dois anos, foram sempre compreensíveis com minhas ausências em reuniões e festinhas. Um obrigada especial ao Rômulo (agradei só dessa vez, tá?) que, sendo entendedor de Marx, tanto me ajudou com dúvidas e conceitos hegelianos na reta final do trabalho.

Ao Departamento de Pós-Graduação em História Social da Cultura da PUC-Rio por ter acreditado no meu projeto, especialmente à professora Margarida de Souza Neves, ao professor Leonardo Miranda e ao meu orientador por terem me estimulado a seguir em frente com Barravento.

Ao pessoal da secretaria do departamento pela eterna paciência e ajuda e ao corpo de professores da pós-graduação. Agradeço especialmente a Leonardo Miranda e Ivana Stolze pelas sugestões bibliográficas e a atenção de sempre.

Ao CNPq, sem o auxílio do qual esta pesquisa não teria sido desenvolvida.

A Luiz Paulino, pelas longas conversas, gravadas ou não, por me apresentar seu lar no Matutu e compartilhar seu pão. Obrigada por sua generosidade intelectual, emocional e espiritual.

A meus pais que sempre me apoiam em tudo, um infinito obrigada. À minha irmã que mesmo de longe me incentivou, me chamando de "cabeção". À Teresita, pela comida gostosa que bem me alimentou enquanto estudava nesses últimos dois anos. À minha avó, a rainha do nosso lar, muito obrigada por estar conosco

Ao Nego, obrigada pelo apoio nas horas de aperto, pelas conversas na janela e pelas opiniões - fundamentadas e não fundamentadas. A troca com você é fundamental para o meu viver. 


\section{Resumo}

Nunes, Raquel Pereira Alberto; Reznik, Luís. Barravento(s): uma análise comparativa de roteiros. Rio de Janeiro, 2011, 165 p. Dissertação de Mestrado - Departamento de História, Pontifícia Universidade Católica do Rio de Janeiro.

Busca-se analisar, comparativamente, dois olhares sobre o filme Barravento (1962): o primeiro de Luiz Paulino dos Santos, captado através de seu roteiro, e o segundo de Glauber Rocha, apreendido a partir de seu roteiro e filme. Ambas as perspectivas dialogam com concepções e tensões presentes no ambiente cultural brasileiro, particularmente na Bahia, em fins da década de 1950 e início dos anos 1960. Pretende-se, através dessa análise, uma reflexão sobre os diversificados olhares acerca da cultura popular, das religiões afro-brasileiras, do papel do intelectual na sociedade e dos conceitos de povo e de alienação durante a época.

\section{Palavras-chave}

Ciclo de cinema baiano - cultura popular - identidade nacional - alienação 


\section{Abstract}

Nunes, Raquel Pereira Alberto; Reznik, Luís (Advisor). Barravento(s): a comparative analysis of screenplays. Rio de Janeiro, 2011, 165 p. Msc. Dissertation - Departamento de História, Pontifícia Universidade Católica do Rio de Janeiro.

It's one intention to analyse the comparison between two different authors' views of the film entiltled Barravento (1962), whose names respectively are Luiz Paulino dos Santos and Glauber Rocha. The first one view was captured only through his original screenplay, whereas, in the case of the second, one chose his views on both screenplay and film. Their both perspectives were based on the Brazilian socio-cultural concepts of those times, mainly in Bahia around late 1950 's and early 1960's. During the analysis, it's one intent to reflect upon the diverse views of pop culture, the concept of people, Afro-Brazilian religions, alienation and also the rolls which intellectuals played in those society were adressed.

\section{Keywords}

Bahia film cycle - pop culture - national identity - alienation 


\section{Sumário}

$\begin{array}{lll}1 \text { Introdução } & 10\end{array}$

1.1 O filme como objeto de pesquisa $\quad 12$

$\begin{array}{ll}1.2 & \text { A história de Barravento } \\ & 18\end{array}$

1.3 Estrutura e fontes do trabalho 20

2 A cultura em efervescência 24

2.1 O Ciclo de Cinema Baiano 24

2.2 A ideia de cultura popular 38

3 O Barravento de Luiz Paulino dos Santos 54

3.1 O depoimento 55

3.2 Apresentação das personagens principais 66

$\begin{array}{lll}3.2 .1 & \text { Firmino } & 66\end{array}$

$\begin{array}{lll}3.2 .2 \text { Cota } & 69\end{array}$

$\begin{array}{ll}3.2 .3 \text { Aruan } & 72\end{array}$

3.2.4 Naína 73

3.3 Impressões gerais do roteiro 76

3.3.1 Aspecto técnico 76

3.3.2 Aspecto linguístico 78

3.3.3 Aspecto lírico-explicativo 80

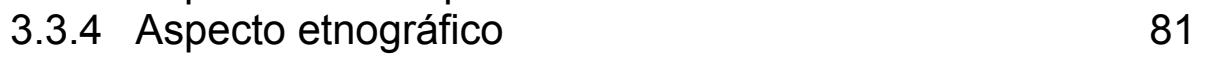

3.3.5 Aspecto religioso 85

3.4 Análise narrativa de quatro cenas 92

3.4.1 Cena um 92

3.4.2 Cena dois 93

3.4.3 Cena três 96

3.4.4 Cena quatro 101 
4 O Barravento de Glauber Rocha 106

4.1 O depoimento - Iniciação 109

4.2 O Barravento de Glauber Rocha 115

4.3 Diferenças fundamentais das personagens 122

$\begin{array}{llr}\text { 4.3.1 Firmino } & 122\end{array}$

4.3.2 Cota 126

4.3.3 Mestre 126

$\begin{array}{ll}\text { 4.3.4 Aruan } & 127\end{array}$

4.3.5 Naína 129

4.3.6 Seu Vicente 130

4.4 Análises das sequências 131

4.4.1 Abertura e créditos 131

4.4.2 Primeira sequência 134

4.4.3 Sequência da rede 136

4.4.4 Sequência do barravento 139

4.4.5 Sequência final 144

5 Conclusão 147

6 Referências bibliográficas 157

$\begin{array}{ll}6.1 \text { Cinema } & 157\end{array}$

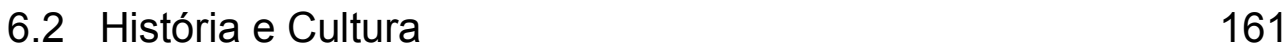

6.3 Técnicos 165

6.4 Entrevistas 165

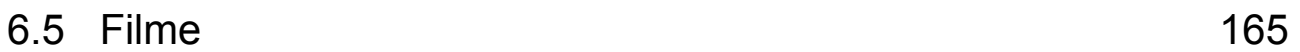

